\title{
Liquid phase separation and rapid dendritic growth of undercooled ternary $\mathrm{Fe}_{60} \mathrm{CO}_{20} \mathrm{Cu}_{20}$ alloy
}

\author{
F. P. Dai ${ }^{1}$. W. L. Wang ${ }^{1} \cdot$ Y. Ruan ${ }^{1} \cdot$ B. Wei ${ }^{1}$
}

Received: 12 September 2017 / Accepted: 11 November 2017 / Published online: 4 December 2017

(c) The Author(s) 2017. This article is an open access publication

\begin{abstract}
Liquid ternary $\mathrm{Fe}_{60} \mathrm{Co}_{20} \mathrm{Cu}_{20}$ alloy was undercooled by up to $357 \mathrm{~K}\left(0.21 T_{\mathrm{L}}\right)$ with glass fluxing method and its rapidly solidified microstructures were investigated by EDS and EBSD technologies. The ternary $\mathrm{Fe}_{60} \mathrm{Co}_{20} \mathrm{Cu}_{20}$ alloy rapidly solidifies with rapid dendritic growth of the primary $\gamma$-Fe phase within 37-243 K undercooling range. When the alloy melt is undercooled to $243 \mathrm{~K}$, an obvious phase separation takes place and the uniform alloy melt separates into ( $\mathrm{Fe}$, $\mathrm{Co}$ )-rich and $\mathrm{Cu}$-rich phases within $243-357 \mathrm{~K}$ undercooling range. The primary $\gamma$-Fe phase takes place in a solid-state phase transformation and becomes $\alpha$-Fe phase in the final microstructure. The microstructure of $\alpha$-Fe phase transforms from coarse dendrite at small undercoolings to equiaxed grain at large undercoolings. EBSD analysis reveals that the coarse $\alpha$-Fe dendrites grows anisotropically with a $\langle 110\rangle$ preferred orientation on condition that undercooling is less than $178 \mathrm{~K}$, whereas no apparent preferred growth orientation is found in the equiaxed grains once undercooling exceeds this critical value. The growth velocity of primary $\gamma$-Fe dendrite increases up to $37 \mathrm{~ms}^{-1}$ as undercooling increases to $243 \mathrm{~K}$, but it decreases as undercooling further increases, ascribing to that the dendrite growth is impeded by phase separation.
\end{abstract}

\section{Introduction}

Dendritic growth has received a great deal of attention from the materials and physics scientists for centuries [1-11]. Over the past few decades, a number of investigators have successfully developed theories to predict the dendritic growth velocity of pure metals and alloys as a function of undercooling [12-17]. As a very important parameter for the solidification theory investigation, the dendritic growth velocity $(V)$ under different undercooling $(\Delta T)$ conditions has been investigated experimentally and theoretically in the field of materials science. The glass fluxing method [7] and some levitation techniques are usually used to experimentally measure the dendritic growth velocity up to now [2, 15-19]. There still exist two questions need to make it clear. First, although the dendritic growth velocity in different alloy systems shows good agreement with theoretical model

\footnotetext{
B. Wei

bbwei@nwpu.edu.cn

F. P. Dai

fpdai@nwpu.edu.cn

1 Department of Applied Physics, Northwestern Polytechnical University, Mail Box 624, West 127, Youyi Road, Xi'an 710072, Shaanxi, People's Republic of China
}

under low undercooling condition, it always deviates from the theoretical model when the alloy melt is undercooled into a high level [5]. Second, it is still difficult to explain the dendrite growth mechanism in the immiscible alloy system. Because the dendrite growth is strongly influenced by the phase separation, the growth mechanism becomes more complicated [7].

It is well known that the ternary $\mathrm{Fe}-\mathrm{Co}-\mathrm{Cu}$ is a typical liquid immiscible alloy within a large composition range, especially in the high undercooling state. The present studies on $\mathrm{Fe}-\mathrm{Co}-\mathrm{Cu}$ alloy system are mainly focused on the thermodynamics calculation of phase diagram and microstructure evolution [20, 21, 22, 23]. However, the dendritic growth velocity of the primary phase in $\mathrm{Fe}-\mathrm{Co}-\mathrm{Cu}$ alloy has not been studied extensively until now. In this work, we studied the dendritic growth and phase separation under different undercooling conditions for the ternary $\mathrm{Fe}_{60} \mathrm{Co}_{20} \mathrm{Cu}_{20}$ alloy using the glass fluxing method. Especially, the dendritic growth velocity, the primary phase $\gamma$-Fe, and the dendrite morphology of $\alpha$-Fe solid-state phase transformed from $\gamma$-Fe in ternary $\mathrm{Fe}_{60} \mathrm{Co}_{20} \mathrm{Cu}_{20}$ alloy were investigated. 


\section{Experimental procedure}

Ternary $\mathrm{Fe}_{60} \mathrm{Co}_{20} \mathrm{Cu}_{20}$ master alloy was prepared from 99.999\% pure $\mathrm{Fe}, \mathrm{Co}$, and $\mathrm{Cu}$ in an ultrahigh vacuum arcmelting furnace. Each sample had a mass of $1 \mathrm{~g}$. As shown in Fig. 1, the selected alloy composition point was marked in ternary $\mathrm{Fe}-\mathrm{Co}-\mathrm{Cu}$ phase diagram $[21,24,25]$. To map this composition point to three corresponding binary phase diagrams, we can find that the highly undercooled $\mathrm{Fe}_{60} \mathrm{Co}_{20} \mathrm{Cu}_{20}$ alloy is involved in the metastable immiscible gap of both $\mathrm{Fe}-\mathrm{Cu}$ and $\mathrm{Co}-\mathrm{Cu}$ binary alloys.

During the glass fluxing experiment, the prepared master alloy sample was placed in an $8 \mathrm{~mm}$ ID $\times 10 \mathrm{~mm}$ $\mathrm{OD} \times 12 \mathrm{~mm}$ alumina crucible containing a suitable amount of $70 \% \mathrm{~B}_{2} \mathrm{O}_{3}+20 \% \mathrm{Na}_{2} \mathrm{~B}_{4} \mathrm{O}_{7}+10 \% \mathrm{CaF}_{2}$ fluxing agent. The chamber was evacuated to $2.0 \times 10^{-5} \mathrm{~Pa}$ and then backfilled with highly purified Ar gas. The alloy was remelted by radiofrequency induction heating under the protection of Argon. The temperature was measured using an infrared pyrometer. The recalesence time during solidification, which was used to measure the dendritic growth velocity, was detected with a photodiode device.

The rapidly solidified $\mathrm{Fe}_{60} \mathrm{Co}_{20} \mathrm{Cu}_{20}$ alloy samples with different undercooling degrees were sectioned, mounted, and polished. Subsequently, the polished samples were etched using the solution of $5 \mathrm{~g} \mathrm{FeCl}_{3}+100 \mathrm{ml} \mathrm{HCl}+100 \mathrm{ml} \mathrm{H}_{2} \mathrm{O}$, and then were examined by a scanning electron microscope (FEI FEG Sirion 200) equipped with an energy-dispersive X-ray spectrometry (Oxford X-Max SDD-50) system and an electron back scattered diffraction (Oxford HKL Channel 5). The differential scanning calorimeter (Netzsch DSC 404C) with a heating rate of $10 \mathrm{~K} \mathrm{~min}^{-1}$ was used to investigate the thermal stability. The crystal structures of the undercooled samples were analyzed by X-ray diffraction (XRD) with $\mathrm{Cu}$ $\mathrm{K} \alpha$ radiation (Rigaku D/Max $2500 \mathrm{~V}$ ).

\section{Results and discussion}

\subsection{Solidification process under moderate undercoolings}

The typical microstructure of the ternary $\mathrm{Fe}_{60} \mathrm{Co}_{20} \mathrm{Cu}_{20}$ master alloy with a backscatter electron image is illustrated in Fig. 2a, which shows that $\alpha$-Fe phase is well-branched dendrites and $(\mathrm{Cu})$ phase locates within the interdendritic spaces. As shown in Fig. 2b, the XRD pattern of the master alloy reveals that it consists of two solid solution phases, namely, bcc $\alpha$-Fe and fcc $(\mathrm{Cu})$.

To clearly understand the solidification process of the ternary $\mathrm{Fe}_{60} \mathrm{Co}_{20} \mathrm{Cu}_{20}$ alloy melt, a high-temperature DSC
Fig. 1 Location of $\mathrm{Fe}_{60} \mathrm{Co}_{20} \mathrm{Cu}_{20}$ alloy in $\mathrm{Fe}-\mathrm{Co}-$ $\mathrm{Cu}$ phase diagram

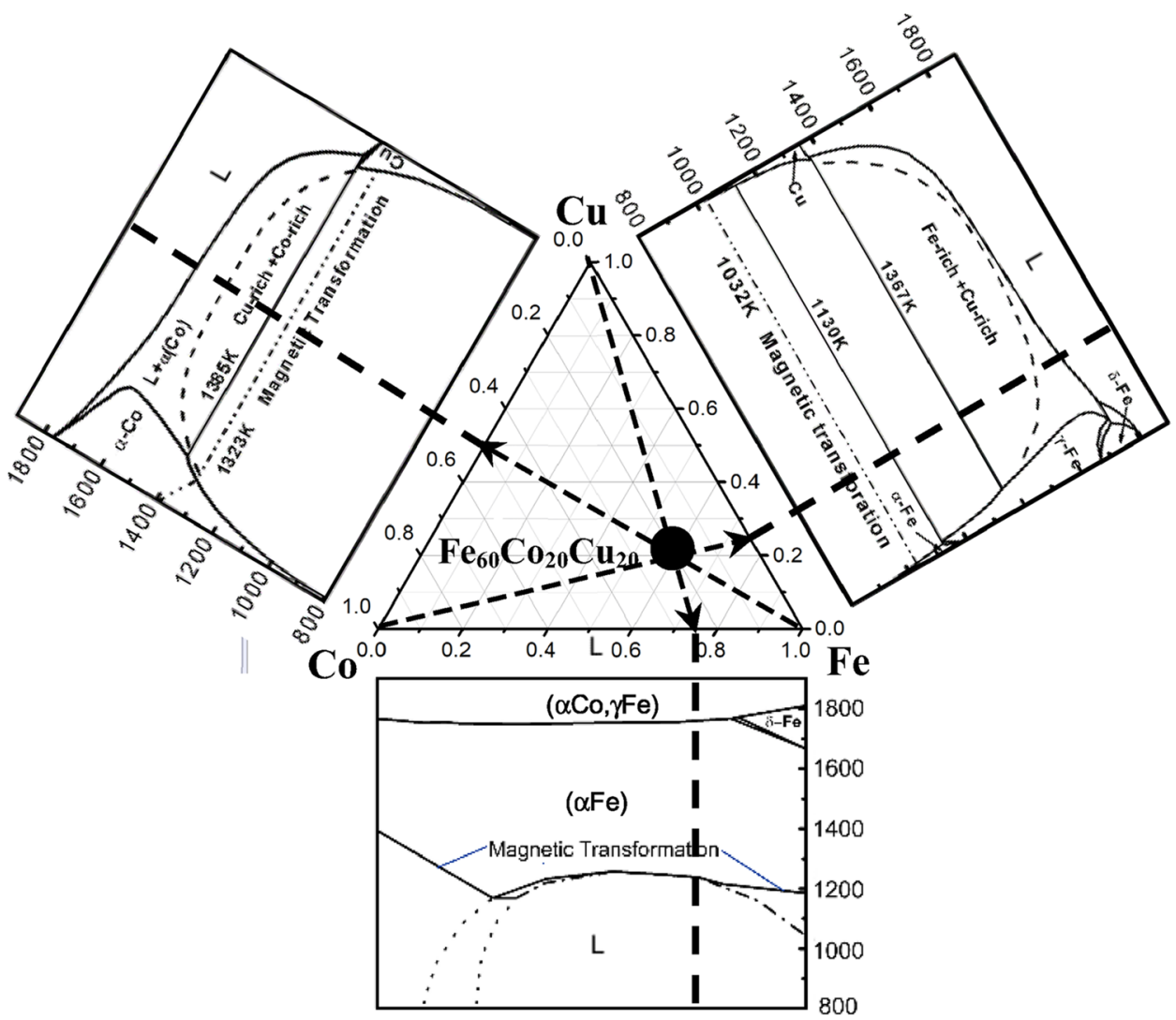



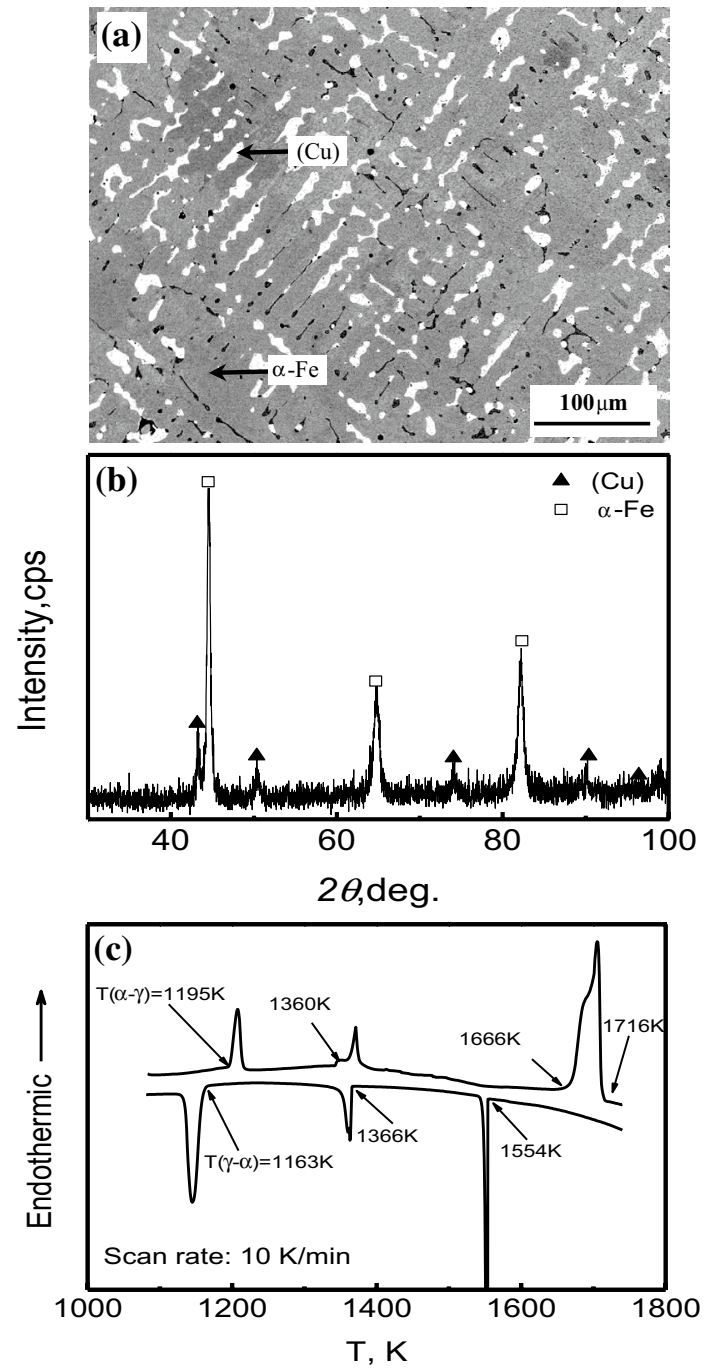

Fig. 2 Structural and thermal analyses of $\mathrm{Fe}_{60} \mathrm{Co}_{20} \mathrm{Cu}_{20}$ master alloy: a typical microstructure of master alloy, $\mathbf{b}$ XRD pattern, and $\mathbf{c}$ DSC curve

thermal analysis is performed at a heating and cooling rate of $10 \mathrm{~K} \mathrm{~min}^{-1}$, which can be considered as a near-equilibrium condition. The sample used in the DSC analysis has a mass of $35 \mathrm{mg}$. As illustrated in Fig. 2c, the typical DSC curves of ternary $\mathrm{Fe}_{60} \mathrm{Co}_{20} \mathrm{Cu}_{20}$ alloy show that the first endothermic peak appears at $1195 \mathrm{~K}$ during the heating process, which was determined to be a solid-state phase transformation of $\alpha$-Fe to $\gamma$-Fe $[19,25]$. The subsequent two endothermic events at 1360 and $1666 \mathrm{~K}$ are related to the melting processes of the $\mathrm{Cu}$-rich and $(\mathrm{Fe}, \mathrm{Co})$-rich phases, respectively, due to their different melting points. The sample will be completely melted once heated up to $1716 \mathrm{~K}$. During the cooling process, one exothermal peak corresponding to the solidification of the primary Fe-rich phase occurs at $1554 \mathrm{~K}$ firstly. Then the $(\mathrm{Cu})$-rich phase starts to solidify, which is related to the exothermic peak at $1366 \mathrm{~K}$.
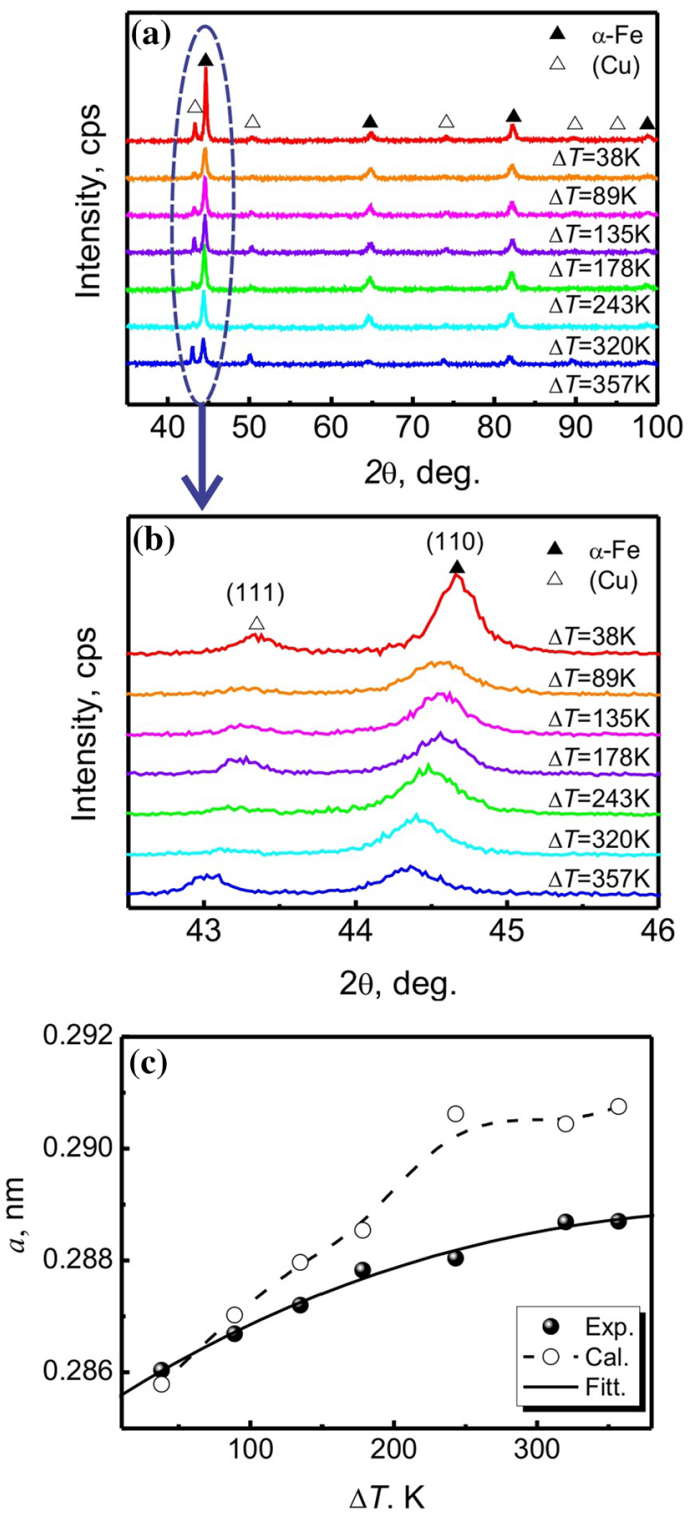

Fig. 3 XRD analyses versus undercooling of ternary $\mathrm{Fe}_{60} \mathrm{Co}_{20} \mathrm{Cu}_{20}$ alloy: a XRD patterns, $\mathbf{b}$ enlarged XRD peaks, and $\mathbf{c}$ lattice constant of $\alpha$-Fe phase

Finally, the martensitic phase transition of $\gamma$-Fe phase to $\alpha$-Fe phase occurs at $1163 \mathrm{~K}$. Therefore, the solidus and liquidus temperatures of $\mathrm{Fe}_{60} \mathrm{Co}_{20} \mathrm{Cu}_{20}$ alloy are determined as 1360 and $1716 \mathrm{~K}$, respectively.

Using the glass fluxing method, the ternary $\mathrm{Fe}_{60} \mathrm{Co}_{20} \mathrm{Cu}_{20}$ alloy melts were undercooled among a broad range. Figure 3 illustrates the XRD patterns for seven rapidly solidified samples with different undercoolings ranged from 38 to $357 \mathrm{~K}$, which demonstrate that all the undercooled $\mathrm{Fe}_{60} \mathrm{Co}_{20} \mathrm{Cu}_{20}$ alloy samples are composed of bcc $\alpha-\mathrm{Fe}$ and fcc $(\mathrm{Cu})$ phases. However, the crystallographic structure of each phase is changed within the experimental undercooling ranges. Figure $3 b$ shows the strongest diffraction peak 
at (110) crystallographic plane for $\alpha$-Fe phase and (111) crystallographic plane for $(\mathrm{Cu})$. In addition, both of their diffraction angles decrease with the increase of undercooling. Figure $3 \mathrm{c}$ shows the relationship between the lattice constant of experimental measurement and calculated result of the $\alpha$-Fe phase at different undercoolings, which illustrates that the lattice constant of the $\alpha$-Fe phase increases
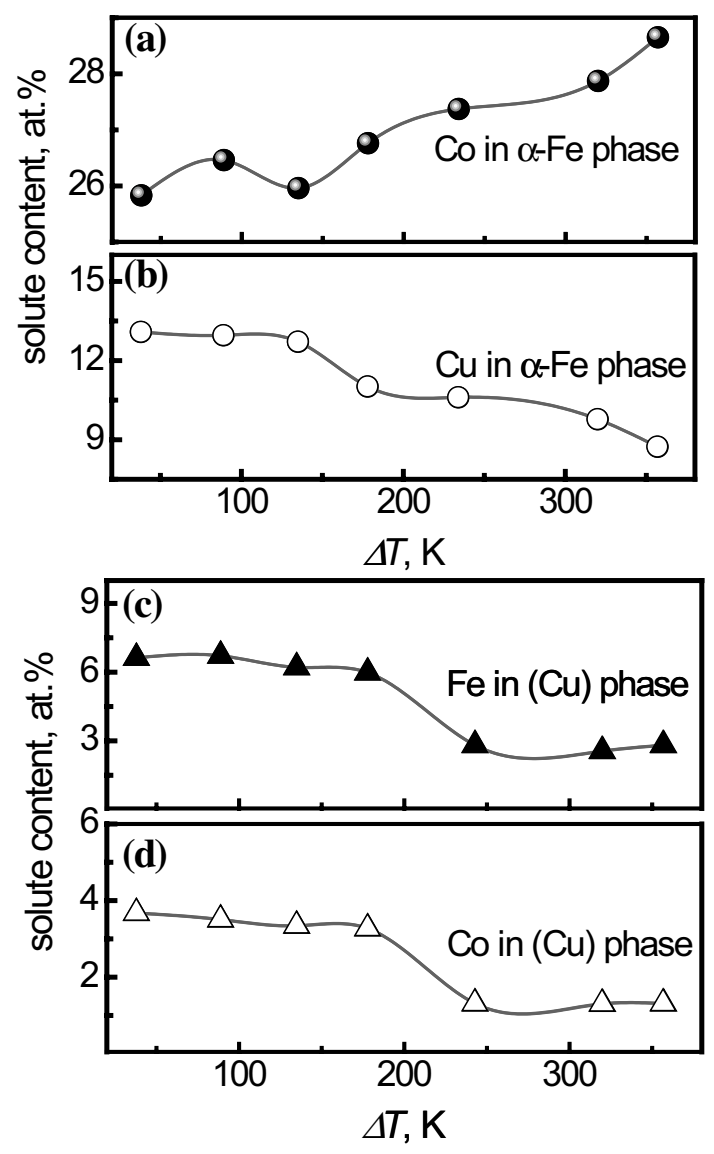

Fig. 4 Solute distribution in ternary $\mathrm{Fe}_{60} \mathrm{Co}_{20} \mathrm{Cu}_{20}$ alloy versus undercooling: $\mathbf{a}, \mathbf{b}$ for $\alpha$-Fe phase, $\mathbf{c}, \mathbf{d}$ for $(\mathrm{Cu})$ phase with the enhancement of undercooling. Zen has predicted that the lattice constant of a solid solution is closely related to the composition of each element within this phase [26]. It can be expressed as follows:

$a=\left[x_{\mathrm{Fe}}\left(a_{\mathrm{Fe}}\right)^{3}+x_{\mathrm{Cu}}\left(a_{\mathrm{Cu}}\right)^{3}+x_{\mathrm{Co}}\left(a_{\mathrm{Co}}\right)^{3}\right]^{1 / 3}$,

where $a$ is the lattice constant, $a_{\mathrm{Fe}}=0.2866 \mathrm{~nm}$, $a_{\mathrm{Cu}}=0.3607 \mathrm{~nm}$, and $a_{\mathrm{Co}}=0.3544 \mathrm{~nm}$ is the lattice constant of pure bcc Fe, pure fcc $\mathrm{Cu}$, and pure bcc Co. $x_{\mathrm{Fe}}$, $x_{\mathrm{Cu}}$, and $x_{\mathrm{Co}}$ is the atomic percent of $\mathrm{Fe}, \mathrm{Cu}$, and $\mathrm{Co}$ in $\alpha-\mathrm{Fe}$ phase, which is determined by EDS and shown in Fig. 4. As illustrated as the circles in Fig. 3c, the predicted lattice constant of the $\alpha-\mathrm{Fe}$ phase is also increased with the rise of undercooling.

The solute contents of different elements in $\alpha$-Fe and $(\mathrm{Cu})$ phases at different undercooling $(\Delta T)$ conditions are shown in Fig. 4. For $\alpha$-Fe phase, the solubility of Co increases with the rise of undercooling, while the solubility of $\mathrm{Cu}$ decreases with the increase of undercooling. When undercooling is $38 \mathrm{~K}$, the concentrations of $\mathrm{Co}$ and $\mathrm{Cu}$ in the $\alpha$-Fe phase are 25.83 and 13.08 at.\%, respectively, whereas when undercooling is up to $357 \mathrm{~K}$, these values become 28.65 and 8.73 at.\%, respectively. Because $\mathrm{Cu}$ is hardly miscible with both $\mathrm{Fe}$ and $\mathrm{Co}$ [27], the solubility of $\mathrm{Cu}$ and $\mathrm{Co}$ in $\alpha$-Fe phase presents an opposite variation tendency when undercooling increases. For $(\mathrm{Cu})$ phase, the solubility for both $\mathrm{Fe}$ and Co decreased with the increase of undercooling, as shown in Fig. 4c, d. Thus, $\mathrm{Fe}$ and $\mathrm{Co}$ are easily miscible, but $\mathrm{Cu}$ is hardly miscible with both $\mathrm{Fe}$ and $\mathrm{Co}$, especially in high undercooling condition.

The microstructures of the ternary $\mathrm{Fe}_{60} \mathrm{Co}_{20} \mathrm{Cu}_{20}$ alloy obtained under different undercooling conditions are shown in Fig. 5. The dark and light phases are identified to be $\alpha$-Fe and $(\mathrm{Cu})$ phases, respectively. Similar to the master alloy, the $\alpha$-Fe phase grows as coarse and well-branched dendritic structures under the small undercooling condition. As displayed in Fig. 5a, when the undercooling rises to $89 \mathrm{~K}$, the longest primary trunk of $\alpha$-Fe phase is measured as $490 \mu \mathrm{m}$.
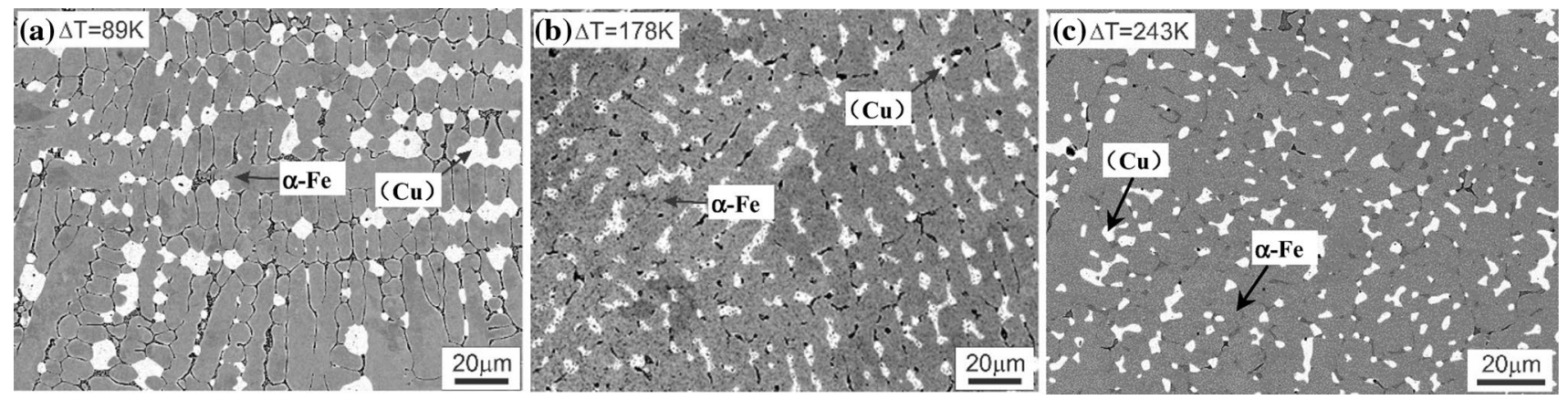

Fig. 5 Homogeneous microstructures without phase separation of ternary $\mathrm{Fe}_{60} \mathrm{Co}_{20} \mathrm{Cu}_{20}$ alloy under moderate undercoolings, a $\Delta T=89 \mathrm{~K}$, b $\Delta T=178 \mathrm{~K}$, and $\mathbf{c} \Delta T=243 \mathrm{~K}$ 
The $(\mathrm{Cu})$ phase with a small quantity of volume fractions is filled to the interdendritic space of $\alpha-\mathrm{Fe}$ dendrites. With undercooling increasing to $135 \mathrm{~K}$, the longest primary trunk of $\alpha$-Fe phase was decreased to approximately $180 \mu \mathrm{m}$. However, after the alloy being undercooled by up to $243 \mathrm{~K}$, a distinct structural transition from dendrites to equiaxed grains occurs. It can be seen from Fig. $5 \mathrm{c}$ that the $\alpha$-Fe phase in the undercooled $\mathrm{Fe}_{60} \mathrm{Co}_{20} \mathrm{Cu}_{20}$ alloy with undercooling of $243 \mathrm{~K}$ formed the fine equiaxed grains. The maximum grain size of the $\alpha$-Fe phase sharply decreased to $25 \mu \mathrm{m}$. The separated $(\mathrm{Cu})$ phase formed as tiny segments and homogeneously distributed along the grain boundary of $\alpha$-Fe phase in the whole sample.

\subsection{Liquid phase separation induced by great undercoolings}

When the undrcooling exceeds $243 \mathrm{~K}$, the $\alpha$-Fe phase formed as the fine grains. Figure 6a shows the microstructure of the whole rapidly solidified sample undercooled by $357 \mathrm{~K}$ $\left(0.21 T_{\mathrm{L}}\right)$, which is the maximum undercooling obtained in this work. It is noticeable that the liquid phase separation obviously occurs under this high undercooling condition. As a result of the Marangoni and Stokes effects [19], the separated $\mathrm{Cu}$-rich droplets migrate and collide with each other. Then, these droplets solidified as a spherical morphology with different sizes and dispersed in $\alpha$-Fe equiaxed grain matrix, as shown in Fig. 6b. Moreover, some separated
(Cu) phase even precipitated to the bottom of the sample and formed a thin sedimentated layer of the $(\mathrm{Cu})$ solid solution phase at the bottom part of the sample, as shown in Fig. 6c. The EDS mapping results for the dispersive $\mathrm{Cu}$-rich droplet marked by the frame in Fig. $6 \mathrm{~b}$ are shown in Fig. $6 \mathrm{~d}-\mathrm{f}$, which indicates that the solid solubility of $\mathrm{Fe}$ and Co is very small in $(\mathrm{Cu})$ phase and $\mathrm{Cu}$ atoms were expelled from $\alpha-\mathrm{Fe}$ equiaxed grain, as presented in Fig. 6f. Therefore, the EDS mapping results further confirm the solute distribution discussed above. In the primary phase matrix, the grain size of $\alpha$-Fe equiaxed grains became tiny with the size of $22 \mu \mathrm{m}$, whereas those $(\mathrm{Cu})$ phase droplets still fill into the interdendritic space of $\alpha$-Fe phase equiaxed grain, as shown in Fig. 6b.

\subsection{Rapid dendritic growth of the primary $\mathrm{Y}$-Fe phase}

To explore the dendritic growth mechanism at different undercoolings, as well as the effect of the phase separation on the dendritic growth, the growth velocity $(V)$ of the primary $\gamma$-Fe phase was carefully measured. Based on the as-measured recalesence time with different undercooling conditions, the dendritic growth velocity of the primary $\gamma$-Fe phase was measured and illustrated in Fig. 7a. When $38<\Delta T<243 \mathrm{~K}$, the growth velocity increases with undercooling and can be expressed by the following function:

$V=3.15 \times 10^{-3} \Delta T^{1.68}$.


Fig. 6 Microstructures of ternary $\mathrm{Fe}_{60} \mathrm{Co}_{20} \mathrm{Cu}_{20}$ alloy at $357 \mathrm{~K}$ undercooling: a microstructure of the whole sample; $\mathbf{b}$ microstructure with separated $\mathrm{Cu}$-rich droplet; $\mathbf{c}$ segregation $\mathrm{Cu}$-rich phase layer at the bottom of the sample framed in a; $\mathbf{d}$ Fe EDS mapping image; e Co EDS mapping image; and $\mathbf{f} \mathrm{Cu}$ EDS mapping image for the $\mathrm{Cu}$-rich droplet framed in $\mathbf{b}$ 


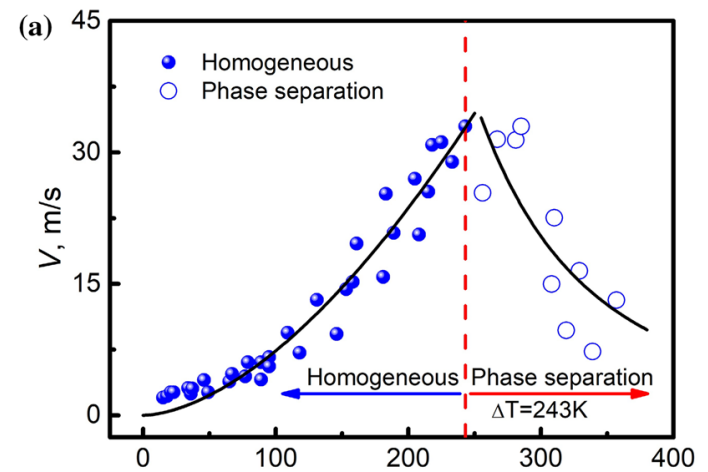

(b)

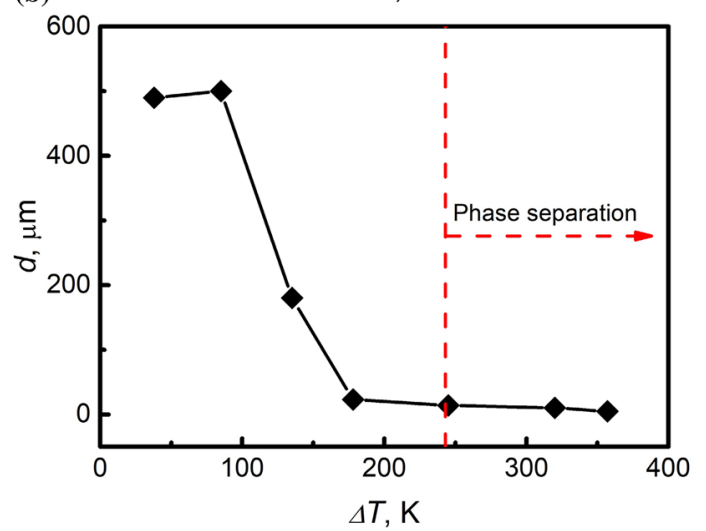

Fig. 7 Dendritic growth of primary $\gamma$-Fe phase versus undercooling: $\mathbf{a}$ dendritic growth velocity and $\mathbf{b}$ grain size of $\alpha$-Fe phase

When $\Delta T=243 \mathrm{~K}$, the growth velocity rises up to the maximum value of $V_{\max }=37 \mathrm{~ms}^{-1}$. However, as the undercooling increases from $243 \mathrm{~K}$ to the maximum experimental undercooling at $357 \mathrm{~K}$, the dendritic growth velocity of the primary $\gamma$-Fe phase decreases from 37 to $13 \mathrm{~ms}^{-1}$. The growth velocity decreases with undercooling and can be expressed as follows:

$V=6.20 \times 10^{9} \Delta T^{-3.21}$.

Once the undercooling exceeds this critical value of $243 \mathrm{~K}$, the solidified alloy exhibits obvious macrosegregation and metastable liquid phase separation. It can be found that the growth velocity of the primary $\gamma$-Fe phase depends on the level of liquid phase separation. Such microstructural transition has a considerable influence on the growth of the primary $\gamma$-Fe phase dendrite.

Furthermore, the dendrite size is also an important parameter to evaluate the dendritic growth and microstructure formation [19, 22]. As mentioned above, the primary $\gamma$-Fe transforms to $\alpha$-Fe after solid-state phase transformation. The morphologies of the primary dendrite that we have observed in the microstructure belong to $\alpha$-Fe phase. In this work, the longest trunk of the dendritic branches was measured to regard the value of the grain size $(d)$ of $\alpha$-Fe phase dendrites. Then, the correlation between the grain size, $d$, and the undercooling, $\Delta T$, is well established, as shown in Fig. 7b. It can be found that the grain size of the $\alpha$-Fe phase dendrite decreases with the increase of undercooling. In the undercooling range from 38 to $89 \mathrm{~K}$, the dendritic trunk of the $\alpha$-Fe phase reaches up to $490 \mu \mathrm{m}$. The coarse dendrite of the $\alpha$-Fe phase grows from the heterogeneous nuclei originated from the crucible wall. With the undercooling increasing from 89 to $178 \mathrm{~K}$, the $\alpha$-Fe phase gradually changes from the dendrite to equiaxed grain. The smallest grain size of the $\alpha$-Fe equiaxed grain is only $11 \mu \mathrm{m}$ under a maximum experimental undercooling of $357 \mathrm{~K}$. Therefore, the grain size decreases rapidly with the rise of undercooling. According to the nucleation theory $[15,16]$, the nucleation rate in the alloy melt increases with the rise of undercooling. Therefore, there are more nuclei formed in the highly undercooled alloy melt than that in the less undercooled alloy melt. In addition, the strong recalescence under higher undercooling conditions can also remelt and break the dendrite arms. However, due to the occurrence of the liquid phase separation induced by the higher undercooling, $\mathrm{Cu}$-rich phase were immiscible with the $\alpha$-Fe phase equiaxed grains, and then, $(\mathrm{Cu})$ solid solution phase would distribute in the front of the $\alpha$-Fe phase and became the barrier against the dendritic growth.

Electron backscatter diffraction (EBSD) technique was applied to characterize the crystalline growth orientation of the dendritic grain of the $\alpha$-Fe phase [23]. Figure 8 presents the pole figures of corresponding solidified samples with undercooling of 89 and $243 \mathrm{~K}$. Figure 8 a shows the pole figures of $\alpha-\mathrm{Fe}$ phase in the solidified sample with undercooling of $89 \mathrm{~K}$. It is evident that the coarse $\alpha-\mathrm{Fe}$ phase dendrites grow obviously with a certain crystalline growth orientation. The statistical orientation angle difference of $\alpha-\mathrm{Fe}$ phase dendrite is concentrated primarily near the vicinity of $38^{\circ}$. This exhibits that the coarse dendrite of $\alpha-\mathrm{Fe}$ phase possesses a remarkable preference for a growth orientation of $\langle 110\rangle$ at small undercooling condition. Figure 8 a shows the $\{100\}$ pole figure of $\alpha-\mathrm{Fe}$ phase in tangential direction for the corresponding solidified sample with undercooling of $89 \mathrm{~K}$. It presents an obvious pole point. Figure $8 \mathrm{~b}$ shows the orientation difference angles of $\{100\}$ at normal direction. The statistical orientation angle difference of $\alpha$-Fe phase dendrite is concentrated to the vicinity of $38^{\circ}$ along normal direction. However, there is a clear difference for the high undercooling. Figure $8 \mathrm{c}$ shows the $\{100\}$ pole figure of $\alpha-F e$ phase in tangential direction for the corresponding solidified sample with undercooling of $243 \mathrm{~K}$ and it has no obvious pole point. For the results of orientation difference angles of $\{100\}$ at normal direction, as shown in Fig. 8d, the statistical orientation angle difference of $\alpha$-Fe phase dendrite is dispersed to a wide angle range along normal direction. In fact, the $\{111\}$ and $\{100\}$ pole 

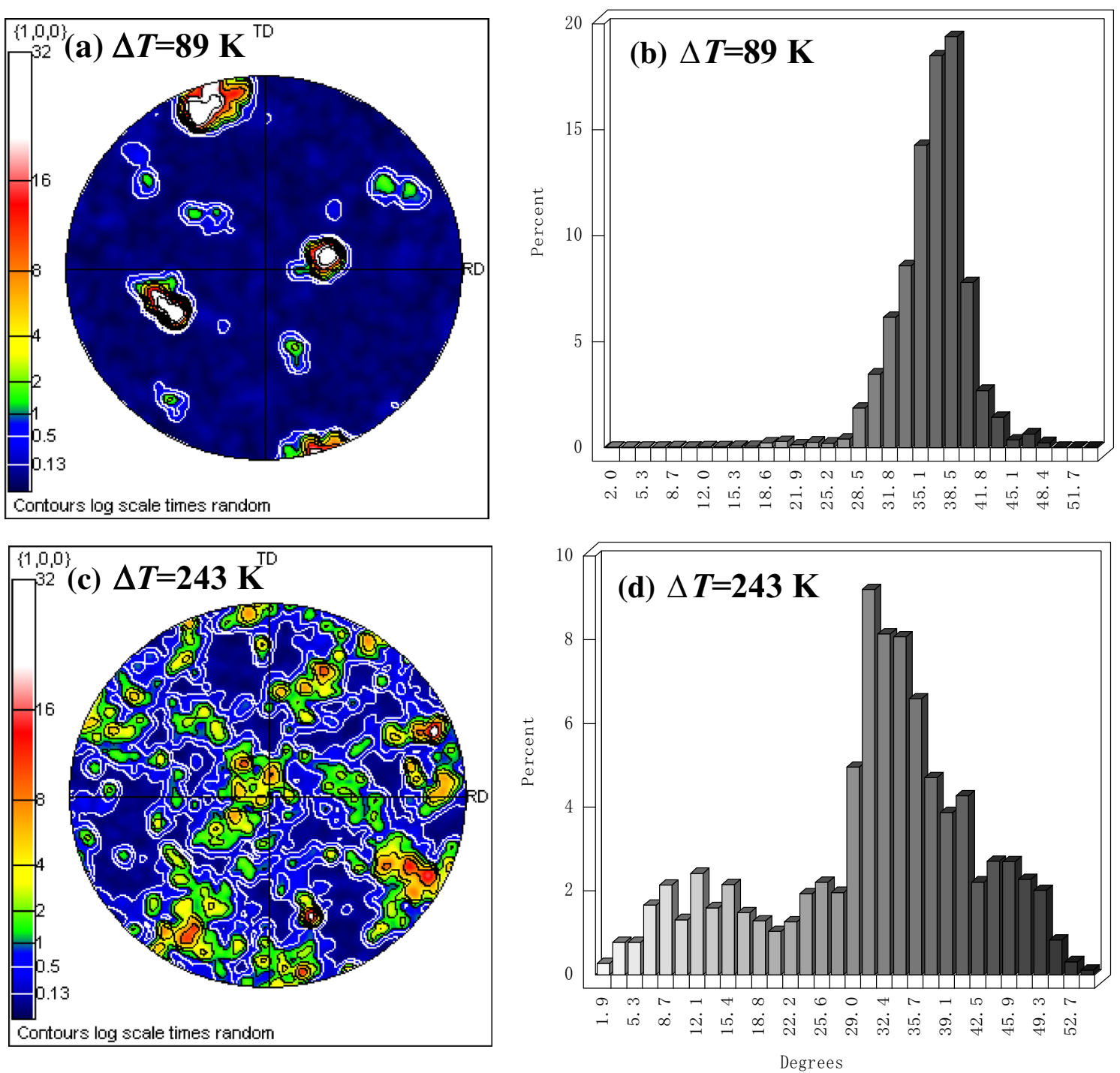

Fig. 8 EBSD pole figures of $\alpha$-Fe phase dendrite grain with different undercoolings. a $\{100\}$ poles figure and $\mathbf{b}$ orientation difference angles corresponding to $\Delta T=89 \mathrm{~K} ; \mathbf{e}\{100\}$ poles figure and $\mathbf{d}$ orientation difference angles corresponding to $\Delta T=243 \mathrm{~K}$

figures of $\alpha$-Fe phase with undercooling of $243 \mathrm{~K}$ do not display any concentrated pole point in any direction. These are also agreeing with the XRD analysis results, as illustrated in Fig. 3a. The (110) plane of $\alpha$-Fe phase presents the strongest diffraction peak than the other diffraction peaks. However, the difference of the diffracted intensity between different crystal planes is decreasing with the increase of undercooling. This exhibits that the coarse dendrite of primary $\alpha$-Fe phase possesses a remarkable preference for a growth orientation of $\langle 110\rangle$ at low undercooling, but the equiaxed grain of $\alpha$-Fe phase under high undercooling condition has not exhibited preferred growth orientation.

\section{Conclusions}

In summary, the glass fluxing method was applied to investigate the rapid dendritic growth of the primary $\gamma$-Fe phase in the undercooled ternary $\mathrm{Fe}_{60} \mathrm{Co}_{20} \mathrm{Cu}_{20}$ alloy within a wide undercooling range from 38 to $357 \mathrm{~K}$. The liquidus and solidus temperatures are determined as 1360 and $1716 \mathrm{~K}$, respectively. The primary $\gamma$-Fe phase takes place in a solid-state phase transformation and become $\alpha$-Fe phase in the final microstructure. The microstructure of the alloy consists of $\alpha-\mathrm{Fe}$ and $(\mathrm{Cu})$ phases. The $\alpha-\mathrm{Fe}$ phase transforms from coarse dendrite to equiaxed grain, 
while phase separation has been observed. The dendritic growth velocity increases as undercooling increases from 38 to $243 \mathrm{~K}$. Once undercooling exceeds $243 \mathrm{~K}$, the dendritic growth velocity began to decrease as undercooling further increases, which is caused by the occurrence of phase separation. The EBSD analyses revealed that the coarse dendrites of the $\alpha$-Fe phase under low undercooling conditions show a $\langle 110\rangle$ preferred growth orientation. However, the equiaxed grains obtained at high undercooling conditions exhibit an isotropically grown pattern.

Acknowledgements This work was supported financially by the National Natural Science Foundation of China (Grant nos. 51671161, 51371150, U1660108, and 51327901) and the Natural Science Foundation Research Project of Shaanxi Province of China (Grant no. 2017JM5116). The authors also wish to acknowledge Dr. W. Löser, Prof. W. J. Xie, Prof. K. K. Song, and Dr. H. S. Jiao for their help.

Open Access This article is distributed under the terms of the Creative Commons Attribution 4.0 International License (http://creativecommons.org/licenses/by/4.0/), which permits unrestricted use, distribution, and reproduction in any medium, provided you give appropriate credit to the original author(s) and the source, provide a link to the Creative Commons license, and indicate if changes were made.

\section{References}

1. J. Warren, Dendritic crystals—rule of thumb breaks down. Nat. Mater. 5, 595-596 (2006)

2. O. Shuleshova, T. Woodcock, H. Lindenkreuz, R. Hermann, W. Loeser, B. Buchner, Metastable phase formation in Ti-Al-Nb undercooled melts. Acta Mater. 55, 681-689 (2007)

3. T. Haxhimali, A. Karma, F. Gonzales, M. Rappaz, Orientation selection in dendritic evolution. Nat. Mater. 5, 660-664 (2006)

4. X. Xu, J. Odqvist, M.H. Colliander, S. King, M. Thuvander, A. Steuwer, P. Hedstroem, Effect of cooling rate after solution treatment on subsequent phase separation during aging of $\mathrm{Fe}-\mathrm{Cr}$ alloys: a small-angle neutron scattering study. Acta Mater. 51, 221-229 (2017)

5. S.B. Luo, W.L. Wang, J. Chang, Z.C. Xia, B. Wei, A comparative study of dendritic growth within undercooled liquid pure $\mathrm{Fe}$ and $\mathrm{Fe}_{50} \mathrm{Cu}_{50}$ alloy. Acta Mater. 69, 355-364 (2014)

6. E. Brener, C. Hüter, D. Pilipenko, D. Temkin, Velocity selection problem in the presence of the triple junction. Phys. Rev. Lett. 99, 105701-105704 (2007)

7. D.Y. Zang, H.P. Wang, F.P. Dai, D. Langevin, B. Wei, Solidification mechanism transition of liquid $\mathrm{Co}-\mathrm{Cu}-\mathrm{Ni}$ ternary alloy. Appl. Phys. A 102, 141-145 (2011)

8. J.X. Fang, B.J. Ding, X.P. Song, Y. Han, Single crystal growth via a grain rotation mechanism within amorphous matrix. Appl. Phys. Lett. 92, 173120-173123 (2008)
9. H. Yin, S.D. Felicelli, L. Wang, Simulation of a dendritic microstructure with the lattice Boltzmann and cellular automaton methods. Acta Mater. 59, 3124-3136 (2011)

10. A. Badillo, D. Ceynar, C. Beckermann, Growth of equiaxed dendritic crystals settling in an undercooled melt. J. Cryst. Growth 309, 197-224 (2007)

11. X.F. Zhang, J.Z. Zhao, H.X. Jiang, M.F. Zhu, A three-dimensional cellular automaton model for dendritic growth in multi-component alloys. Acta Mater. 60, 2249-2257 (2012)

12. J. He, J.Z. Zhao, L. Ratke, Solidification microstructure and dynamics of metastable phase transformation in undercooled liquid $\mathrm{Cu}-\mathrm{Fe}$ alloys. Acta Mater. 54, 1749-1757 (2006)

13. P. Peng, X.Z. Li, J.G. Li, Y.Q. Su, J.J. Guo, On oscillatory microstructure during cellular growth of directionally solidified Sn-36 at.\%Ni peritectic alloy. Sci. Rep. 6, 24315 (2016)

14. W.L. Wang, Y.H. Wu, L.H. Li, N. Yan, B. Wei, Homogeneous granular microstructures developed by phase separation and rapid solidification of liquid Fe-Sn immiscible alloy. J. Alloys Compd. 693, 650-657 (2017)

15. W. Kurz, D.J. Fisher, Fundamental of Solidification, 4th edn. (Trans Tech Publications Ltd., Switzerland, 1998), p. 63

16. W.J. Boettinger, S.R. Coriell, A.L. Greer, A. Karma, W. Kurz, M. Rappaz, R. Trivedi, Solidification microstructures: recent developments, future directions. Acta Mater. 48, 43-70 (2000)

17. D. Tourret, C.A. Gandin, A generalized segregation model for concurrent dendritic, peritectic and eutectic solidification. Acta Mater. 57, 2066-2079 (2009)

18. Z.C. Xia, W.L. Wang, S.B. Luo, B. Wei, Liquid phase separation and rapid dendritic growth of highly undercooled ternary $\mathrm{Fe}_{62.5} \mathrm{Cu}_{27.5} \mathrm{Sn}_{10}$ alloy. J. Appl. Phys. 117, 054901 (2015)

19. S. Akamatsu, S. Bottin-Rousseau, G. Faivre, E.A. Brener, Scaling theory of two-phase dendritic growth in undercooled ternary melts. Phys. Rev. Lett. 112, 105502 (2017)

20. M. Bamberger, A. Munitz, L. Kaufman, R. Abbaschian, Evaluation of the stable and metastable $\mathrm{Cu}-\mathrm{Co}-\mathrm{Fe}$ phase diagrams. Calphad 26, 375-384 (2002)

21. T. Nishizawa, K. Ishida, in Phase Diagrams of Binary Copper Alloys, ed. by P.R. Subramanian, D.J. Chakrabarti, D.E. Laughlin (ASM, New York, 1994), p. 138

22. S. Walder, P.L. Ryder, Rapid dendritic growth in undercooled Ag-Cu melts. Acta Metall. Mater. 43, 4007-4013 (1995)

23. Y. Ruan, F.P. Dai, Rapid dendrite growth subjected to multi-solute trapping in an undercooled Fe-based quaternary alloy. Intermetallics 25, 80-85 (2012)

24. L.J. Swartzendruber, in Phase Diagrams of Binary Copper Alloys, ed. by P.R. Subramanian, D.J. Chakrabarti, D.E. Laughlin (ASM, New York, 1994), p. 167

25. T. Nishizawa, K. Ishida, in Phase Diagrams of Binary Iron Alloys, ed. by H. Okamoto (ASM, New York, 1993), p. 93

26. E. Zen, Am. Miner. 41, 523 (1956)

27. F.P. Dai, B. Wei, Core-shell microstructure formed in the ternary $\mathrm{Fe}-\mathrm{Co}-\mathrm{Cu}$ peritectic alloy droplet. Chin. Sci. Bull. 54, 1287-1294 (2009) 